\title{
JUVENTUDE E FORMAÇÃO: A POLÍTICA PÚBLICA DE FORMAÇÃO PROFISSIONAL COMO CENÁRIO
}

\author{
Manuella Castelo Branco Pessoa \\ Universidade Federal da Paraíba (UFPB)
}

\author{
Maria de Fatima Pereira Alberto \\ Universidade Federal da Paraíba
}

Orlando Junior Viana Macêdo

Faculdade Paraíso (FAP) e Faculdade Juazeiro do Norte (FJN)

\section{Antonia Picornell Lucas}

Universidad de Salamanca

\begin{abstract}
Resumo
O estudo objetivou caracterizar a formação oferecida pela Política Pública de Formação Profissional por meio de uma pesquisa documental nos programas que a compõem. Foram acessados: relatórios, legislação, manuais, atas, projetos políticos pedagógicos, dados de inserção e sites. Realizou-se uma Análise de Conteúdo Temática e os dados foram analisados meio do programa QDA Miner. Os resultados apontaram que a Política colabora com a qualificação profissional juvenil, mas também serve ao capital na medida em que massifica os cursos profissionalizantes e utiliza-os como forma de enriquecimento e produção de mão de obra barata. Conclui-se ser necessário superar a visão reducionista de que a falta de qualificação é a responsável pelo desemprego, deixando-se desviar das determinações estruturais e de precarização. Discute-se a necessidade de ultrapassar a certificação vazia, contemplando o jovem como sujeito social nesse processo de formação, para que, assim, esta possa acontecer concretamente.
\end{abstract}

Palavras-chave: jovens; formação profissional; políticas públicas.

\section{YOUTH AND EDUCATION: THE PUBLIC POLICY FOR PROFESSIONAL EDUCATION AS A SCENARIO}

\begin{abstract}
This article aims to characterize the education provided by the Public Policy for Professional Education. There were analyzed reports on the programs implemented, legislation, manuals, minutes, the political pedagogical projects of the courses, youth professional insertion and websites. Data analysis was the Thematic Content Analysis and the software QDA Miner. It was apparent from the data that the Policy brings with at least two sides: one, the collaboration with the professional qualification, since it offers courses and pedagogical spaces; and on the other hand, it also serves capital as it massifies the vocational courses and uses them as a form of enrichment and production of cheap labor. Thus, it is necessary to overcome the reductionist view that the lack of qualification generates unemployment, allowing itself to deviate from the structural determination and precariousness. It is necessary to go beyond empty certification, contemplating the youth as a social subject, so that this can happen concretely.
\end{abstract}

Keywords: youth; professional education; public policy. 


\title{
JUVENTUD Y FORMACIÓN: LA POLÍTICA PÚBLICA DE FORMACIÓN PROFESIONAL COMO ESCENARIO
}

\begin{abstract}
Resumen
Este artículo objetivó caracterizar la formación ofrecida por la Política Publica de Formación Profesional, a través de una investigación documental. Se accedió a los: informes, legislación, actas, proyectos políticos pedagógicos, datos de inserción y sitios web, analizado desde el análisis temático de contenido y del software QDA Miner. Se hizo evidente que esta política colabora con la cualificación profesional ofreciéndoles cursos y espacios de aprendizaje; y, a la vez sirve al capital, masificando los cursos profesionales y utilizándolos como un medio de producción de trabajo precarizado. Por lo tanto, el reto para esta política consiste en superar la visión reduccionista de que la falta de cualificación genera desempleo, desviándose de las limitaciones estructurales y de la precariedad. Es necesario superar la certificación vacía que se ofrece actualmente y reconocer al joven como sujeto social en este proceso de formación, de tal manera que la política pueda cumplir con su función.

Palabras clave: jóvenes; formación profesional; políticas públicas.
\end{abstract}

\section{INTRODUÇÃO}

O presente artigo tem como objetivo caracterizar a formação oferecida pela Política Pública de Formação Profissional. Para tanto, assume-se como posicionamento teórico a perspectiva histórico-cultural seguindo a ótica vigotskiana, considerando que os sujeitos são históricos, concretos, marcados por uma cultura, criadores de ideias e consciência que, ao produzirem e reproduzirem a realidade social são ao mesmo tempo produzidos e reproduzidos por ela (Vygotski, 2006). Dessa forma, como afirmam Tommasi (2014) e Bernardim (2013), a forma de conceber a juventude também vai nortear a formulação de políticas públicas voltadas a esse público.

As políticas voltadas para a juventude no Brasil são encontradas principalmente nas áreas de educação e formação profissional, porém, percebese que parte destas políticas tomou como base a diminuição da criminalidade e da pobreza, sendo concebidas como um antídoto à marginalidade (Nascimento, 2014; Souza, Paiva \& Oliveira, 2013; Bernardim, 2013). Diante de tais investimentos, indaga-se: Quem é o jovem que acessa a política? Que tipo de formação vem sendo oferecida por esta? Tais questionamentos partem do princípio que, aparentemente, há um jogo de interesse entre capital e sociedade, que vai ditar o lugar que essas políticas ocuparão culturalmente e na vida desses jovens (Netto, 2001).

A juventude que emerge na literatura é aquela que tenta aliar trabalho e estudo (Linhares, 2014; Silva, 2010) e que, mesmo com um aumento na média de anos escolares cursados, a busca por emprego ainda se faz presente de forma precoce na vida desses jovens. Autores como Porchman (2013) e Pelissari (2012) mostram que o aumento de níveis escolares não vem sendo suficiente para potencializar a geração de trabalho, visto que há um contexto de baixo investimento em tecnologias e precarização do mercado de trabalho. 
Os jovens são também, segundo os estudos de Puerta e Aznarde (2013) e Nascimento (2014), os que mais sofrem com a questão do desemprego, pois são protagonistas de um cenário de falta de formação profissional que os leva a ocupar vagas de trabalhos extremamente precarizadas e sem perspectivas de ascensão. Geralmente são os jovens pobres que ingressam mais cedo no mundo do trabalho, assim une-se também a questão das necessidades e busca por melhores condições de vida (Tommasi, 2014). Isso demarca questões já tão conhecidas de desigualdade social no país, como salienta Linhares (2014), e dessa forma, para suprir suas necessidades e de suas famílias um grande número de jovens se submete cada vez mais cedo ao mundo do trabalho, mesmo que este não se dê de forma legalizada.

Destarte, problematiza-se que é preciso se qualificar para conseguir entrar no mercado de trabalho embora a qualificação por si só não garanta a entrada e permanência no mesmo. Apesar disso, como apontam Frigotto (2013) e Porchman (2013), sem qualificação a inserção se mostra ainda mais difícil. Dessa forma, está posta a necessidade de se criar medidas sociais para garantir a entrada no mercado de trabalho e em nome do crescimento da nação, isso atingirá diretamente a vida do jovem (Alves, 2013). Tais medidas se materializam por meio de tentativas de colocar os jovens como parte constituinte da agenda das políticas públicas (Amorim, 2013; Souza et al., 2013), e assim pensar políticas que combatam o risco social. São ações de ordem internacional, como: Programa Mundial de Ação para Juventude (PMAJ); e outras que acontecem no âmbito nacional, como: Comissão Especial de Políticas para a Juventude (Cejuvente), Secretaria Nacional de Juventude (SNJ), o Conselho Nacional de Juventude (CONJUVE), Proposta de Emenda à Constituição (PEC) da Juventude, o Estatuto da Juventude.

Tais ações geraram políticas públicas que funcionam como ferramentas de efetivação de direitos (Souza et al., 2013), se dando através de programas voltados à formação profissional, ao aumento escolaridade, o combate ao risco, o controle, entre outros. Mas, como atenta Nascimento (2014), em um país em que o trabalho se encontra fortemente presente na vida juvenil, torna-se um desafio elaborar políticas que enfrentem a inserção precarizada no mercado de trabalho por aqueles que legalmente já estão aptos a trabalhar. Dessa forma, o que se vê a partir dos anos 2000, é o surgimento e reformulações de políticas já existentes como uma forma de dar conta da formação profissional e demais aspectos elencados acima.

A implementação do Programa Nacional de Estímulo ao Primeiro Emprego, é uma das tentativas, vindo com o objetivo de promover a geração de postos de trabalho para jovens e prepará-los para o mercado de trabalho. Outro ponto considerado como avanço foi a elaboração da Agenda Nacional de Trabalho Decente pelo Brasil, entendendo como aquele que é adequadamente remunerado, exercido em condições de liberdade, equidade e segurança (Souza 
et al., 2013), compromisso assumido a partir de 2003, com o auxílio da Organização Internacional do Trabalho (OIT) e Conselho Nacional de Juventude (CONJUVE).

A criação do Programa Nacional de Inclusão de Jovens em 2005 tornou-se, também, outra medida posta como vantagem pelo governo brasileiro, pois incorporou a maior parte dos programas federais. Seu foco está voltado à elevação da escolaridade e ao estímulo à conclusão do Ensino Fundamental, a qualificação profissional inicial e ao desenvolvimento de ações comunitárias (Souza et al., 2013). Outro avanço nos esforços do país foi a criação do Estatuto da Juventude em 2013, que traz a garantia do direito à Profissionalização, trabalho e renda, no seu Artigo 40.

Apesar dessas iniciativas, diversos limites são encontrados nas avaliações, o principal deles é que a política continua sendo gerida de forma independente por diferentes ministérios. Logo, vê-se uma política fragmentada, cindida em: uma parte da política é assumida pelo empresariado que assume a formação mais rápida e aligeirada; outra parte assumida pelo Estado via ensino técnico, promovendo uma formação de longa duração, mais completa, com maiores possibilidades de ascensão profissional (Amorim, 2013).

Há um entendimento de que tais políticas tanto estão voltadas para o controle ou dominação (Nascimento, 2014; Dalarosa \& Souza, 2014), quanto para o atendimento de determinadas demandas dos setores subalternos da sociedade. Tal situação expressa o traço contraditório dessas políticas, caracterizando-se como um território de antagonismo que as atravessam (Netto, 2011). A reflexão crítica do formato da política para juventude leva autores como Dalarosa e Souza (2014), Amorim (2013) e Silva (2010) a apontar que por trás de tudo isso, a formação profissional dos jovens é realizada segundo a justificativa de combate a vulnerabilidade e pobreza, servindo na verdade, como estratégia para o desenvolvimento econômico. Estas são utilizadas como ferramentas de qualificação, mas continuam a propagar o discurso de que o jovem ocioso é potencialmente perigoso, sendo postas como a salvação para a juventude.

Tais considerações levam a pensar que juventude é essa que procura a política e ao mesmo tempo é alvo desta? Assim sendo, a relação entre o jovem e a política se dá vinculada às suas condições de vida, ao contexto o qual pertence e a educação que prepara o sujeito para a sociedade. Ou seja, é uma relação cultural, uma vez que esta é expressão do processo histórico, objetivada nos instrumentos culturais dispostos na forma material e psicológica (Vigotski, 1995). Isso posto, o presente artigo refere-se à juventude que tem a Política Pública de Formação Profissional enquanto contexto de desenvolvimento, assumindo que estas auxiliam na constituição desses sujeitos. 


\section{MÉTODO}

Com a finalidade de caracterizar a formação oferecida pela Política Pública de Formação Profissional, tomou-se como cenário a Política realizada na cidade de João Pessoa-PB. Esta conta com: o Programa Jovem Aprendiz (PJA); Programa Nacional de Inclusão de Jovens - modalidade Urbano (PJU); Curso Técnico Integrado (EMI); Programa de Educação de Jovens e Adultos (PROEJA); Programa de Educação pelo Trabalho para a Saúde (PET Saúde); Programa de Educação Tutorial (PET); e Superintendência Regional do Trabalho (SRT), que atua como uma instituição de proteção. Estas serviram de cenário para o estudo realizado.

\section{Instrumentos}

Foi realizada uma coleta de documentos relacionados a cada programa e cursos que compõe a Política em questão. Segundo Sá-Silva, Almeida e Guindani (2009), a pesquisa documental tem como característica a busca por informações em documentos que ainda não receberam tratamento científico, ou seja, as fontes primárias que remetem aos dados originais. Através deles, é proporcionada uma relação direta com os fatos a serem analisados. Assim, foram acessados documentos como: relatórios acerca dos programas realizados, legislação, manuais, atas, projetos políticos pedagógicos dos cursos, dados de inserção de jovens, cartilhas e sites.

\section{Procedimentos}

Foi realizado contato via telefone com cada instituição e agendadas reuniões de esclarecimento sobre a pesquisa e material disponível. Os coordenadores das instituições participantes assinaram um termo de consentimento livre e esclarecido, de acordo com o determinado pela Resolução No 466/2012. Na sequência teve início o levantamento de todos os documentos que puderam ser disponibilizados por cada uma das instituições. Em alguns casos, foi permitida a realização da cópia do documento, em outros foi permitido apenas o acesso ao documento na própria instituição.

Para analisar os dados, inicialmente foi realizada uma Análise de Conteúdo Temática (Bardin, 2009), com temas gerados a partir dos dados empíricos, tendo como finalidade conhecer todo o material disponível e captar os temas presentes; seguida pela submissão dos achados ao software QDA Miner (Qualitative Data Analysis). A Análise de Conteúdo Temática se deu a partir da extração de temas de alta relevância que emergiram no material, chegando aos temas: Marco legal, Caracterização, Formação ofertada e Inserção. Já o QDA Miner foi utilizado da seguinte forma: criaram-se as variáveis de acordo com a análise de conteúdo, depois foram criados os códigos para identificação e auxílio na interpretação do material com ajuda do programa. 


\section{RESULTADOS}

Os documentos serão descritos por meio de blocos temáticos que emergiram a partir da análise de dados com o intuito de verificar as singularidades de cada programa, bem como suas similaridades. Os blocos que emergiram foram: Marco legal, caracterização das políticas, formação ofertada e inserção no mercado de trabalho, que serão descritos a seguir.

\section{Marco legal: legislação nacional e a proximidades entre as Políticas Públicas}

No material referente à Legislação Nacional, emergiram os códigos: ministérios e determinação da lei. O marco legal proporciona a definição do público alvo, determina a ação da política em nível nacional, e mostra ainda que as Políticas acessadas se encontram vinculadas a três Ministérios: o da educação, o da saúde e o do trabalho e emprego. No código determinação da lei, foi possível acessar informações que identificam as mesmas, bem como os requisitos impostos por elas delineando seus públicos alvo. É possível visualizar um maior detalhamento do que emergiu na Tabela 1:

Tabela 1. Marco legal acerca da Política de Formação profissional

\begin{tabular}{|c|c|c|c|c|}
\hline Nome & Número/Ano & O que diz a Lei & Responsável & Requisitos \\
\hline PJA & $\begin{array}{l}\text { Lei no. } \\
10.097 / 2000 \\
\text { Decreto no } \\
5.598 / 2005\end{array}$ & $\begin{array}{l}\text { Que empresas de médio } \\
\text { e grande porte } \\
\text { contratem jovens entre } \\
14 \text { e } 18 \text { anos. } \\
\text { Modificou a idade de } \\
\text { inserção, estendendo } \\
\text { dos } 14 \text { aos } 24 \text { anos. }\end{array}$ & TEM & $\begin{array}{l}14 \text { a } 24 \\
\text { anos; } \\
\text { Ensino } \\
\text { Fundamental } \\
\text { incompleto. }\end{array}$ \\
\hline PJU & $\begin{array}{l}\text { Lei no } \\
11.129 / 2005 \\
\text { (revogada) } \\
\text { Lei no } \\
11.692 / 2008\end{array}$ & $\begin{array}{l}\text { Institui o Projovem; cria } \\
\text { o Conselho Nacional da } \\
\text { Juventude - CNJ e a } \\
\text { Secretaria Nacional de } \\
\text { Juventude } \\
\text { Amplia a idade para } 15 \\
\text { a } 29 \text { anos; Promover a } \\
\text { reintegração } \\
\text { educacional, } \\
\text { qualificação profissional; } \\
\text { desenvolvimento } \\
\text { humano. }\end{array}$ & MEC & $\begin{array}{l}18 \text { a } 29 \\
\text { anos; } \\
\text { Ensino } \\
\text { Fundamental } \\
\text { incompleto. }\end{array}$ \\
\hline PROEJA & $\begin{array}{l}\text { Decreto NO } \\
5.840 / 2006\end{array}$ & $\begin{array}{l}\text { Cursos de formação } \\
\text { inicial e continuada de } \\
\text { trabalhadores; educação } \\
\text { profissional técnica de } \\
\text { nível médio. }\end{array}$ & MEC & $\begin{array}{l}\text { A partir os } 18 \\
\text { anos; } \\
\text { Ensino } \\
\text { Fundamental } \\
\text { incompleto. }\end{array}$ \\
\hline PET & $\begin{array}{l}\text { Lei } \\
11.180 / 2005\end{array}$ & $\begin{array}{l}\text { Fomentar grupos de } \\
\text { aprendizagem tutorial } \\
\text { mediante a concessão } \\
\text { de bolsas de iniciação }\end{array}$ & MEC & $\begin{array}{l}\text { Não há idade } \\
\text { pré- } \\
\text { estabelecida; } \\
\text { Cursando a }\end{array}$ \\
\hline
\end{tabular}




\begin{tabular}{|c|c|c|c|c|}
\hline \multicolumn{4}{|c|}{ científica } & \multirow{2}{*}{$\begin{array}{l}\text { graduação. } \\
\text { Não há idade } \\
\text { pré- } \\
\text { estabelecida; } \\
\text { Cursando a } \\
\text { graduação. }\end{array}$} \\
\hline $\begin{array}{l}\text { PET- } \\
\text { Saúde }\end{array}$ & $\begin{array}{l}\text { Portaria } \\
\text { Interministerial } \\
\text { no } 1.802 / 2008\end{array}$ & $\begin{array}{l}\text { Fomentar grupos de } \\
\text { aprendizagem tutorial } \\
\text { na Estratégia Saúde da } \\
\text { Família. }\end{array}$ & MS e MEC & \\
\hline EMI & $\begin{array}{l}\text { Lei 11.892/ } \\
2008\end{array}$ & $\begin{array}{l}\text { Cria os Institutos } \\
\text { Federais de Educação, } \\
\text { Ciência e Tecnologia; } \\
\text { Art. 60: integração e } \\
\text { verticalização da } \\
\text { educação básica à } \\
\text { educação profissional. }\end{array}$ & MEC & $\begin{array}{l}\text { Não há idade } \\
\text { pré- } \\
\text { estabelecida; } \\
\text { Ensino } \\
\text { Fundamental } \\
\text { completo. }\end{array}$ \\
\hline
\end{tabular}

Tais dados demonstram que a Política de formação usa como principais filtros de acesso a questão da idade e do nível de escolarização do jovem, sendo o mais baixo o ensino fundamental incompleto e o mais alto estar cursando uma graduação. Também demonstram algumas particularidades no momento que algumas assumem a formação profissional dual (formação técnica + prática profissional), enquanto outras apostam na combinação formação básica + formação técnica.

Caracterização dos programas que compõem a Política Pública de Formação Profissional

Na categoria geral Caracterização, foi possível identificar três códigos de análise: objetivos, tipos de formação e o programa em João Pessoa. As similaridades e distanciamentos nos objetivos das políticas, podem ser visualizado na Tabela 2:

Tabela 2. Objetivos dos Programas de Formação Profissional

\begin{tabular}{lcccc}
\hline Nome & $\begin{array}{c}\text { Formação } \\
\text { Profissional }\end{array}$ & $\begin{array}{c}\text { Inserção no } \\
\text { mercado }\end{array}$ & $\begin{array}{c}\text { Reintegrar à } \\
\text { escola }\end{array}$ & Cidadania \\
\hline PJA & $X$ & $X$ & - & - \\
PJU & $X$ & $X$ & $X$ & $X$ \\
PET & $X$ & $X$ & - & $X$ \\
PET-Saúde & $X$ & $X$ & - & - \\
EMI & $X$ & $X$ & - & - \\
PROEJA & $X$ & $X$ & $X$ & - \\
\hline
\end{tabular}

Dentre as similaridades, identifica-se que todos têm como objetivo promover a formação e aprendizagem profissional, em nível técnico, uns aliados ao nível médio, outros aliados ao ensino superior. A inserção no mercado de trabalho é um discurso presente na legislação de todos os programas. Percebese que é objetivo de dois dos programas estudados a reintegração ao processo educativo, trabalhando, segundo seus manuais, com a tentativa de trazer o 
jovem (e o adulto, no caso do Proeja) de volta ao ensino regular. Apenas dois dos programas entre os estudados referem-se diretamente à promoção de cidadania em seus objetivos: o PJU e o PET, que defendem que promover a formação dos jovens é também formar a partir da garantia de cidadania afirmando desenvolver experiências de participação cidadã, e uma formação crítica e atuante.

Vale salientar que o PJA se coloca como um programa voltado à oferta de uma formação teórico-metódica, que significa que a formação se volta exclusivamente a uma área técnica, as questões do avanço na escolarização não é algo priorizado em Lei, ficando, muitas vezes em segundo plano. Outra vertente pode ser vista através do EMI, PET e PET-Saúde que estão voltados a outro público, mantendo como foco a continuidade da escolarização. O primeiro volta-se ao aluno de ensino médio, ofertando a educação nível médio aliada a uma formação técnica. Os últimos têm como alvo alunos universitários que buscam por um complemento à formação acadêmica, voltando-se para extensão e/ou pesquisa.

Dentro do código tipos de formação, emergiram as características e requisitos de inserção de cada programa. Foi perceptível que todos eles exigem certo nível de escolaridade, em alguns a exigência é maior, outros usam a escolaridade justamente como um atrativo para o público alvo, com o discurso da necessidade do retorno à escolarização como forma de cidadania e também como busca de qualificação profissional para conseguir maiores chances no mercado de trabalho.

Em relação aos programas em Joao Pessoa, foi possível identificar que a Política Pública de Formação Profissional é gerida por diferentes instituições nesta cidade. O PJA na cidade de João Pessoa-PB é oferecido pelo: Sistema S (Serviço Nacional de Aprendizagem Industrial-SENAI, Serviço Nacional de Aprendizagem Comercial-SENAC, Serviço Nacional de Aprendizagem em Transportes-SENAT e Serviço Nacional de Aprendizagem do Cooperativismo-SESCOOP), uma Entidade sem Fins Lucrativos e duas ONGs. O programa passou a ser executado na cidade a partir dos anos de 2005, segundo consta em documentos fornecidos pela SRT/PB. Porém se faz necessário fazer uma ressalva a respeito do Projeto Integrado de Formação Profissional, que só foi implementado nos anos de 2010, executado apenas pelo SENAI. Este, por sua vez, foi idealizado com o objetivo de possibilitar o acesso de jovens egressos do PETI, Projovem Adolescente e, posteriormente, os que estão no CREAS/MSE ao PJA. No início do Programa, em 2005, a Paraíba contava com 151 aprendizes. No ano de 2014, João Pessoa contou com 2.818 aprendizes, a Paraíba com o total de 4.185 aprendizes.

Os cursos ofertados através do PJA na cidade de João Pessoa são: Serviços administrativos, telemática, vendas, hotelaria, auxiliar de alimentação, logística, práticas bancárias, produção industrial, telesserviços, eletrotécnica, mecânica, vestuário e impressor offset. Segundo consta no Manual da Aprendizagem 
(2009), o oferecimento de um curso deve ser condizente com a demanda local. Dessa forma, verificou-se que há um predomínio dos cursos na área administrativa, na telemática e indústria.

Foi possível identificar também os bairros onde os jovens atendidos no Programa moram, possibilitando perceber que estes advêm de diversas áreas da cidade, e algumas vezes de cidades vizinhas. Quando analisamos esses bairros, com base na Topografia de João Pessoa (Sposati, 2010), temos uma variação de -0.80 (bairro Padre Zé) a 0,69 (bairro Expedicionários) no Índice de Desenvolvimento Humano (IDH) destes. Ao analisarmos a autonomia dos bairros onde se localizam os Núcleos, vemos que há uma variação de -0,94 (bairro Grotão) a 0,12 (bairro Expedicionários). Entendendo que a autonomia foi medida por Sposati (2010) a partir de oito variáveis que analisaram o rendimento dos chefes de família por domicílio em intervalos de classe, sendo possível verificar a partir dela a relação entre a concentração populacional em relação à exclusão de autonomia e condição de renda. Os bairros citados anteriormente, são lugares de exclusão, como aponta Sposati (2010), o baixo IDH e autonomia refletem as restrições pelas quais essa população passou em relação à escolaridade, renda e qualidade de vida.

Quanto ao PJU, os documentos encontrados na coordenação deste programa revelam que este passa a ser executado na cidade de João Pessoa nos anos de 2005. A partir de 2009, passa pelas modificações de acordo com o regimento nacional, adquirindo o formato tal como é atualmente. No ano de 2005, João Pessoa tinha como meta o atendimento de 3.900 jovens, porém esta meta não foi atingida. Seguindo a determinação do Decreto No 6.629/2008, no ano de 2009, a tentativa era de atingir uma meta de 4.000 inscrições, sendo esta meta ultrapassada, chegando aos 5.200 inscritos.

$\mathrm{Na}$ vigência 2013-2014, a meta permaneceu de 4.000 inserções no Projovem Urbano, sendo ofertadas 200 vagas em cada uma das vinte escolas municipais, chamadas de Núcleos, que executam o programa. Estes estão situados em diversas áreas da cidade, com características comuns, por exemplo: encontrou-se uma variação de -0.80 a 0,77 em relação ao IDH (Sposati, 2010); a autonomia dos bairros onde se localizam os Núcleos variou de $-0,79$ a 0,81. Ou seja, mais uma vez observa-se que são bairros que possuem um baixo IDH, baixa autonomia, estando esses jovens localizados em lugares que tem como uma das características a exclusão (Sposati, 2010), no qual há um acesso precário aos estudos, baixa escolaridade, uma baixa renda familiar e qualidade de vida.

Os arcos ocupacionais ofertados pelo PJU devem ser escolhidos com base nas necessidades locais, segundo o Manual Operacional (2008), porém, não foram acessados na coordenação do programa documentos que remetessem ao processo dessa escolha. Dessa forma, o município conta com cursos nas áreas de: construção e reparo, educação, turismo e vestuário. Ao efetuar matrícula no 
PJU, é feito um levantamento das preferências por parte dos jovens em relação aos arcos ocupacionais oferecidos, e a partir daí é decidido qual arcos será executado em cada Núcleo.

Os documentos referentes ao PET e ao PET-Saúde, foram coletados na Pró-reitoria de Graduação (PRG) do Campus I da UFPB e juntamente aos coordenadores de cada projeto. Os documentos versam sobre a criação dos programas, as modalidades e a que cursos se destinam. Os detalhes podem ser vistos na Tabela 3:

Tabela 3. Caracterização do PET e PET-Saúde

\begin{tabular}{ccll}
\hline Tipo & Início & \multicolumn{1}{c}{ Subprojetos } & \multicolumn{1}{c}{ Composição } \\
\hline PET & 2010 & PET Conexões & Tutor \\
& 2012 & $\begin{array}{l}\text { PET computação, } \\
\text { PET física }\end{array}$ & $\begin{array}{l}12 \text { estudantes } \\
\text { bolsistas } \\
\text { PET farmácia } \\
\end{array}$ \\
& 2013 & PET elétrica & \\
\hline PET-Saúde & 2005 & $\begin{array}{l}\text { Pró-Saúde I } \\
\text { Pró-Saúde II }\end{array}$ & Tutor; \\
& 2008 & $\begin{array}{l}\text { Preceptor; } \\
\text { Saúde da Família }\end{array}$ & Estudantes \\
& 2009 & Vigilância Sanitária & \\
& 2010 & Saúde Mental & \\
& 2012 & Rede Cegonha & Atenção ao Câncer de colo \\
& 2014 & e de mama & \\
& & Pessoa com Deficiência & \\
& Urgência e Emergência & \\
& &
\end{tabular}

O que se percebe em relação ao PET é que atualmente cada um dos programas ofertados estão primordialmente voltados a áreas específicas do saber, aceitando apenas discentes dos respectivos cursos ao qual estão vinculados. Estes abarcam em geral os seguintes cursos de graduação: física, farmácia, engenharias, ciências da computação, geografia, história, letras, pedagogia, química e ciências sociais. Foi possível perceber ainda que, pelo menos no que é registrado, estes tentam executar atividades de ensino, pesquisa e extensão paralelamente, como é determinado por Lei.

Já o PET-Saúde apresenta uma maior a variedade de projetos oferecidos, atendendo a cursos diversificados. Tais projetos voltam-se primordialmente às ações na Atenção Básica da Saúde, atendendo a diversas áreas dentro do campo da saúde, e possibilitando o contato de alunos de variados cursos com a realidade profissional encontrada na rede básica de saúde. Estes também se encontram voltados a atender os objetivos que são determinados pela lei, visto que é parte da atividade do jovem que se encontra inserido no PET-Saúde participar das atividades práticas propostas por cada projeto.

Em relação ao EMI e ao PROEJA, os documentos foram acessados na coordenação responsável pelos respectivos programas no IFPB. A partir daí, foi 
possível verificar o número de jovens que são aceitos por ano em cada curso e também informações a respeito da carga horária exigida em cada curso. Segundo consta nos documentos, os cursos ofertados através do EMI são: Contabilidade (sendo inseridos 40 jovens por ano); Controle ambiental (34 jovens por ano); Edificações (38 jovens por ano); Eletrotécnica (68 jovens por ano); Eletrônica (38 jovens por ano); e Mecânica (38 jovens por ano). Já o PROEJA oferece apenas o curso de Técnico em Eventos ofertando 40 vagas por ano.

Bases da formação ofertada: atendendo os interesses de quem?

Na categoria geral Formação, emergiu o código planos pedagógicos, onde foi possível identificar informações acerca dos objetivos de cada curso, missão e detalhamento do conteúdo acessado pelos jovens em seus respectivos cursos. Para tanto, foi preciso levar em conta as diferenças nas estruturas dos programas aqui estudados (Tabela 4).

Tabela 4. Bases da formação ofertada pelos programas que compõem a Política de Formação

\begin{tabular}{|c|c|c|c|c|}
\hline \multirow[b]{2}{*}{ Programa } & \multicolumn{4}{|c|}{ Bases da formação ofertada } \\
\hline & Objetivo & $\begin{array}{l}\text { Formação } \\
\text { geral }\end{array}$ & $\begin{array}{c}\text { Formação técnica } \\
\text { específica }\end{array}$ & $\begin{array}{c}\text { Formação } \\
\text { comportament } \\
0\end{array}$ \\
\hline PJA & $\begin{array}{l}\text { Proporcionar as } \\
\text { competências } \\
\text { para o exercício } \\
\text { profissional; } \\
\text { Formação ética } \\
\text { e de valores }\end{array}$ & $\begin{array}{l}\text { Português e } \\
\text { matemática. } \\
\text { Direitos } \\
\text { humanos e } \\
\text { trabalhistas }\end{array}$ & $\begin{array}{l}\text { Competências e } \\
\text { funções de cada } \\
\text { profissão; } \\
\text { Atividade a ser } \\
\text { realizada; Poucos } \\
\text { detalhes de } \\
\text { execução; } \\
\text { Oferta prática na } \\
\text { empresa; }\end{array}$ & $\begin{array}{l}\text { Ética e moral; } \\
\text { Higiene } \\
\text { pessoal; } \\
\text { Educação } \\
\text { fiscal e do } \\
\text { consumo; } \\
\text { Sexualidade; } \\
\text { Autoestima; } \\
\text { Postura }\end{array}$ \\
\hline PJU & $\begin{array}{l}\text { Promover a } \\
\text { reintegração ao } \\
\text { processo } \\
\text { educacional, } \\
\text { qualificação } \\
\text { profissional e } \\
\text { Desenvolviment } \\
\text { o humano. }\end{array}$ & $\begin{array}{l}\text { Formato EJA: } \\
\text { português, } \\
\text { matemática, } \\
\text { ciências } \\
\text { humanas, } \\
\text { ciências da } \\
\text { natureza e } \\
\text { língua } \\
\text { inglesa; } \\
\text { Orientação } \\
\text { cidadã; }\end{array}$ & $\begin{array}{l}\text { Discussão sobre o } \\
\text { mundo do } \\
\text { trabalho; } \\
\text { Competências e } \\
\text { funções de cada } \\
\text { profissão; } \\
\text { Atividade a ser } \\
\text { realizada; } \\
\text { Poucos detalhes } \\
\text { de execução; } \\
\text { Apenas um curso } \\
\text { oferta estágio; }\end{array}$ & $\begin{array}{l}\text { Desenvolvime } \\
\text { nto de valores } \\
\text { e } \\
\text { comportamen } \\
\text { to ético. } \\
\text { Autoestima }\end{array}$ \\
\hline EMI & $\begin{array}{l}\text { Preparar } \\
\text { profissionais } \\
\text { cidadãos com } \\
\text { formação } \\
\text { humanística e }\end{array}$ & $\begin{array}{l}\text { Português, } \\
\text { matemática, } \\
\text { química, } \\
\text { biologia, } \\
\text { educação }\end{array}$ & $\begin{array}{l}\text { Competências e } \\
\text { funções de cada } \\
\text { profissão; } \\
\text { Atividade a ser } \\
\text { realizada; }\end{array}$ & $\begin{array}{l}\text { Higiene; } \\
\text { Segurança no } \\
\text { trabalho }\end{array}$ \\
\hline
\end{tabular}




\begin{tabular}{|c|c|c|c|c|}
\hline & tecnológica & $\begin{array}{l}\text { física, } \\
\text { história, } \\
\text { filosofia, } \\
\text { inglês, } \\
\text { sociologia e } \\
\text { artes; } \\
\text { Trabalho e } \\
\text { educação; } \\
\text { Empreendedo } \\
\text { rismo }\end{array}$ & $\begin{array}{l}\text { Oferta de estágio } \\
\text { em todos; }\end{array}$ & \\
\hline PROEJA & $\begin{array}{l}\text { Educar } \\
\text { profissionais- } \\
\text { cidadãos } \\
\text { competentes } \\
\text { tecnicamente, }\end{array}$ & $\begin{array}{l}\text { Formato EJA: } \\
\text { português, } \\
\text { matemática, } \\
\text { ciências } \\
\text { humanas, } \\
\text { ciências da } \\
\text { natureza e } \\
\text { língua } \\
\text { inglesa; }\end{array}$ & $\begin{array}{l}\text { Competências e } \\
\text { funções técnicas }\end{array}$ & - \\
\hline PET & $\begin{array}{l}\text { Desenvolver } \\
\text { atividades } \\
\text { acadêmicas que } \\
\text { contribuam para } \\
\text { elevação da } \\
\text { qualidade da } \\
\text { formação dos } \\
\text { alunos. }\end{array}$ & $\begin{array}{l}\text { Ampliação e } \\
\text { aprofundame } \\
\text { nto dos } \\
\text { conteúdos da } \\
\text { grade } \\
\text { curricular dos } \\
\text { cursos de } \\
\text { graduação. }\end{array}$ & $\begin{array}{l}\text { Vivência prática } \\
\text { nas } \\
\text { correspondentes } \\
\text { áreas } \\
\text { profissionais para } \\
\text { integração no } \\
\text { mercado de } \\
\text { trabalho. }\end{array}$ & $\begin{array}{l}\text { Desenvolvime } \\
\text { nto de valores } \\
\text { éticos; } \\
\text { Melhor } \\
\text { qualificação } \\
\text { como pessoa } \\
\text { humana. } \\
\text { - }\end{array}$ \\
\hline $\begin{array}{l}\text { PET } \\
\text { Saúde }\end{array}$ & $\begin{array}{l}\text { Formar } \\
\text { profissionais } \\
\text { para a atuação } \\
\text { na Atenção } \\
\text { Básica. }\end{array}$ & $\begin{array}{l}\text { Ampliação e } \\
\text { aprofundame } \\
\text { nto dos } \\
\text { conteúdos } \\
\text { que integram } \\
\text { a grade } \\
\text { curricular dos } \\
\text { respectivos } \\
\text { cursos de } \\
\text { graduação. }\end{array}$ & $\begin{array}{l}\text { Vivência prática } \\
\text { nos serviços de } \\
\text { atenção básica. }\end{array}$ & \\
\hline
\end{tabular}

Em resumo, o que emerge na formação geral diz respeito a conteúdos típicos escolares (para o PJA, PJU, EMI e PROEJA) e referentes a especificidades das graduações contempladas pelo PET e PET Saúde. As formações específicas encontram-se voltadas a aprendizagem de competências referentes a cada curso profissionalizante. A maioria refere-se ainda à execução de um estágio relacionado à área de inserção dos respectivos cursos. Além disso, a formação comportamental esteve presente de forma unânime a formação ética, moral e de valores, alguns chegando até ao ensinamento de higiene no ambiente de trabalho. 
Jovens efetivados: números sobre a inserção no mercado de trabalho

A maioria dos programas estudados não possui ou não disponibilizaram registros a respeito da inserção dos seus egressos no mercado de trabalho. Todavia, foi possível acessar por meio da SRT informações referentes ao PJA, contemplando informações acerca dos setores fiscalizados, das cotas por setor e da região da cidade em que as empresas notificadas se encontram. Os dados da SRT mostram que o setor que mais contrata aprendizes é o Imobiliário e da construção, com 320 aprendizes contratados no ano de 2013, seguido pela indústria (101 aprendizes) e pelo setor de Transporte (90 aprendizes).

No PJA SENAI também foi possível acessar uma lista na qual encontravase descrito o encaminhamento e acompanhamento de egressos do programa para as empresas. As informações referiam-se as empresas contratantes, a ocupação, a quantidade de jovens encaminhados e o programa ao qual estava vinculado, o número de jovens admitidos e seus respectivos programas, e também o cargo que iria ocupar na empresa. Desta feita, verificou-se que o curso que mais conseguiu inserir jovens egressos no mercado de trabalho foi o de mecânica, sendo também o que mais formou jovens, seguido pelo curso de Assistente Administrativo e o de Artes gráficas. Chamou atenção ainda o curso de costura industrial, que além de ter um número baixo de jovens participantes, não conseguiu inserir nenhum dos jovens egressos no mercado de trabalho.

\section{DISCUSSÃO}

A partir do objetivo de caracterizar a formação oferecida pela Política Pública de Formação Profissional, a análise documental promovida neste artigo revela que os programas que compõem a Política de Formação Profissional têm como objetivo central formar os jovens profissionalmente e inseri-los no mercado de trabalho. A maioria deles tem como finalidade ofertar formação teórica combinada à formação prática, mas o debruçar nesses documentos mostrou que estes possuem níveis diferentes de formação técnica e atribuem diferentes sentidos a formação prática. Foi possível verificar, assim como Alves (2013), que se recorre ao sistema educativo para a preparação de técnicos, transformando a escola em local de reprodução das relações sociais de produção. Tais achados corroboram também o já constatado por Amorim (2013), que há uma formação que é realizada de forma aligeirada e outra tem uma maior duração. Isso implica formação de um técnico com melhores condições de qualificação em detrimento de outro que vai atender a demandas mais emergenciais.

Foi possível verificar também que há especificidades em relação ao público a quem é ofertada a política. As restrições se dão no sentido etário e em relação ao nível de escolarização, tanto que algumas delas trabalham com uma idade limite de inserção. A questão do nível de escolaridade é a que se torna mais marcante, já que está presente em todas elas, e chama a atenção para o fato de 
que, para ter acesso a tais políticas é necessário também alguns requisitos, apresentando um nível mínimo de instrução, sendo o mais baixo nesse caso o ensino fundamental incompleto.

Tal situação suscita questões já levantadas por Linhares (2013) e Porchman (2013), na qual alimenta-se um mito de que a não inserção no trabalho se dá pela ausência de capacitação escolar, deixando a parte a discussão sobre a escola precária que é ofertada e ainda sobre o sistema produtivo que reflete a ideologia capitalista. Estes direcionam ao jovem a responsabilidade pela não inserção, pela certificação vazia e apressada, e por não saber aproveitar as oportunidades (Dalarosa \& Souza, 2014; Nascimento, 2014). Esse é o lado perverso das Políticas Públicas: são oferecidas, supostamente para atender às demandas das classes subalternas, na medida exata em que elas podem ser refuncionalizadas para o interesse do capital (Netto, 2011)

Dessa forma, reforça-se a dupla experiência de marginalidade social sofrida pelo jovem que tenta acessar a Política de Formação, como bem aponta Bernardim (2013): a dificuldade de concluir o ensino médio e precária inserção ocupacional. Levando-se em conta que é a partir dessa materialidade que o jovem se constitui (Vigotski, 2006), tem-se então um jovem que se forma a partir dessa marginalidade sofrida, de direitos negados, de inserções precárias, e o mais grave, se sentem responsáveis por tal situação, atribuindo a si a falta de sucesso no mercado de trabalho.

A qualificação profissional é tratada em todas as políticas como uma chave para o sucesso, um aumento nas chances no mercado de trabalho, alcançado através de uma formação técnica a mais, mesmo para os que já cursam uma graduação. A qualificação retratada nos documentos é composta por ensinamentos da ordem teórica e da ordem prática. Ela é tratada nessa diversidade de programas que foram acessados, ora como um programa de curso técnico, com oferecimento de diploma referente a esse nível, e com o diferencial de passar por um estágio ou experiência prática; ora como um complemento à formação acadêmica, tentando uma conexão com a prática de cada profissão através de estágios na rede pública de saúde ou em outras áreas de acordo com o programa.

A profissionalização emerge nos documentos como salvação para a vida desses jovens, promovendo a crença de que o Estado fez a sua parte (Nascimento, 2014), adquirindo muito mais um caráter de prestação de favor do que de efetivação de direitos. Tal concepção, como assinala Vigotski (2006), constrói uma relação cultural com o jovem que participa dessa política, que se apropria do que ali the é ensinado, constituindo-se como trabalhador a partir de tais relações. Isso corrobora o que defende Netto (2011), ao verificar que o papel das políticas sociais é a preservação e controle da força de trabalho. Ao agir assim o Estado exerce o papel de mediador, no conflito entre capital e 
trabalho, através das políticas sociais age na preservação e controle da força de trabalho, um suporte sócio-político.

Através das políticas sociais, o Estado burguês procura administrar as expressões da "questão social" de forma a atender às demandas da ordem monopólica conformando, pela adesão que recebe de categorias e setores cujas demandas incorpora, sistema de consenso variáveis, mas operantes. Dessa forma, pondera-se que, quando o Estado intervém sobre a "questão social", o faz a fragmentando-a e parcializando-a (Netto, 2011). Tudo isso é respaldado ainda pelo discurso de que faltam profissionais qualificados, como aponta Pelissari (2012), remetendo a formação profissional como um processo individualizado, reforçando que o trabalhador deve estar em constante formação e preparo para o trabalho (Silva, 2010).

De maneira geral, a formação técnica referente às questões teóricas não fica clara na maioria dos documentos analisados, tratando esse aspecto de forma pouco aprofundada ou apenas indícios do que é trabalhado, uma vez que alguns tratam de temas específicos. É interessante $O$ fato de a formação comportamental fazer parte também da formação teórica/técnica/prática. Em diversos planos de cursos foram encontradas temáticas relacionadas à higiene pessoal e no trabalho, ética e valores, moral e relações interpessoais. O comportamento é posto como uma forma de acessar o mercado de trabalho, e de se manter nele; os jovens, por sua vez, irão se apropriar desse discurso, internalizando que é preciso adquirir tais características para que possam se manter ou acessar o mercado de trabalho (Vigotski, 1995).

Essa tentativa de regular o comportamento juvenil também não é algo recente, pelo contrário, as políticas são reconhecidas na literatura como uma forma de controlar e também de definir a juventude (Nascimento, 2014; Dalarosa \& Souza, 2014). O disciplinamento via formação se dá no sentido de adequação do jovem às demandas produtivas, como apontam Dalarosa e Souza (2014), apelando para a alienação intelectual e moral. Dessa forma, sofrem uma inclusão que é excludente, pois são formados de maneira aligeirada, para serem capazes de se adaptar facilmente, podando as possibilidades de autonomia, fornecendo ao capital a força de trabalho disciplinada.

A oferta da prática é um ponto que merece atenção também, já que esta se dá de formas variadas a depender do programa específico. Ela recebe o nome de estágio, de prática, de atividade de extensão, a maioria tem uma carga horária já fixada. Algumas possuem uma dinâmica mais rígida, postos de trabalho são ocupados. Mas no caso do PJU ela é bem complicada de ser identificada, já que é considerada atividade prática uma visita ao ambiente de trabalho, não havendo garantia de estágios em todos os arcos ocupacionais.

O que é possível perceber é que, a política deveria se dá numa perspectiva de garantia de direitos (Nascimento, 2014; Amorim, 2013), mas essa temática desaparece ao longo de cada manual, relatório, site, entre outros documentos 
acessados. Vê-se uma política fragmentada, sem continuidade, bem menos lê-se sobre uma realização de avaliação constante destas. Além disso, ela carrega em seus próprios documentos o ranço da juventude vista como um problema, que precisa se modificar e aprender a se comportar se quiserem ser contratados.

Como bem aponta Tommasi (2014), a inquietação da juventude é tomada como um problema social, e a forma de sanar tal problema, evitando o risco de acomodação, vêm através do trabalho. Do lado do capital, é necessária mão de obra barata para ocupar os cargos precarizados e qualificada para os cargos mais elevados. Dessa forma, é transmitido ao jovem que ele precisa se qualificar, que - Estado oferta a oportunidade através das políticas públicas e que ele, o jovem, deve atuar para incluir-se (Nascimento, 2014).

Assim, a Política de formação ocupa pelo menos duas funções, primeiro a de acesso à qualificação profissional - possibilitando certificação técnica, melhoras nas condições de trabalho, relações sociais, carreira, sua ausência agrava a situação dos jovens (Linhares, 2014; Souza et al., 2013; Bernardim, 2013). A segunda diz respeito a função de atender também aos interesses do capital, fornecendo uma formação pautada na transmissão de conhecimento, enriquecimento do capital, possibilitando uma inclusão no primeiro momento, excluindo em seguida por conta da precária formação, alimentando o fetiche da profissão (Dalarosa \& Souza, 2014; Puerta \& Aznarde, 2013; Pelissari, 2012).

Problematiza-se também sobre que tipo de jovem e de trabalhador esta Política vem formando e como eles se apropriam do que recebem nessa Política. Entendendo esse sujeito como histórico e marcado pelas relações sociais (Vigotski, 2006), os jovens que são formados carregam as marcas que essa Política imprime: de um jovem que precisa se moldar ao mercado de trabalho e aos interesses do capital, responsabilizado pela sua inserção ou não no mercado, e que não pode ficar parado, visto que sua formação dificilmente será suficiente para mantê-lo no mercado de trabalho.

\section{DECLARAÇÃO DE CONFLITOS DE INTERESSE}

Os autores declaram que não há quaisquer conflitos de interesse entre os autores em relação a publicação deste artigo na referida revista.

\section{CONSIDERAÇÕES FINAIS}

A partir do exposto, percebe-se que a Política Pública Formação Profissional traz consigo um lado de colaboração com a qualificação profissional juvenil, possibilitando o trabalho em detrimento ao desemprego; mas também serve ao capital a medida em que massifica os cursos profissionalizantes e utiliza-os como forma de enriquecimento e produção de mão de obra barata. 
Os documentos analisados permitiram caracterizar a formação oferecida pela Política Pública de Formação Profissional, revelando em suas entrelinhas questões preocupantes. Em relação ao jovem, foi possível vislumbrar uma política voltada aos que tem a partir dos 14 anos, mas que precisam atender a um nível de escolaridade mínima para ser inserido; ao jovem que abandonou o sistema escolar, mas que precisa retomar os estudos para conseguir se inserir no mercado; e ainda a jovens que tem acesso a um melhor sistema educativo, sendo destinada a estes uma formação com melhores condições de qualificação e de maior duração. A formação ofertada, por sua vez, se mostrou ainda muito atrelada ao ensino de como comportar-se, secundarizando sua função de acesso a direitos, se mostrando ainda assistencialista.

Dessa forma, a Política encontra como desafio superar a análise reducionista de que a falta de qualificação é que gera o desemprego, deixar de desviar-se das determinações estruturais e de precarização, ultrapassando a certificação vazia que oferta atualmente, para que assim possa acontecer concretamente. É preciso contemplar o jovem enquanto sujeito social, histórico, que produz e é produzido por essas relações sociais em todas as áreas do seu desenvolvimento, para além dessa formação lacônica e insuficiente. Assim, a Política Pública de Formação Profissional enquanto contexto de desenvolvimento proporciona a esses jovens uma formação que está aquém do necessário, e auxilia na constituição desses sujeitos formando via disciplinamento, se colocando enquanto uma oportunidade ao invés de garantia de direitos.

Entre as limitações e dificuldades enfrentadas ao longo do estudo, destaca-se o difícil acesso aos documentos, a falta de notificações e dados incompletos. A maioria das instituições não dispõem de documentos que revelem o acompanhamento dos jovens, tampouco há informações sobre o perfil destes jovens ao entrarem nos programas, o que dificulta analisar qual jovem que vem buscando a política. Como possibilidade de estudos futuros, sugere-se realizar pesquisas diretamente com os jovens, de forma a caracterizar quem a busca para compreender e modificar a política com a finalidade de que ela atenda de forma mais satisfatória as necessidades do jovem em formação.

\section{REFERÊNCIAS}

Alves, L. A. M. (2013). Ensino técnico: Uma necessidade ou uma falácia? Notas para a compreensão da filosofia do ensino técnico em Portugal e no Brasil. Historia e Educação, 41(17), 103-122. http://dx.doi.org/10.1590/S223634592013000300007.

Amorim, M. L. (2013). Exigência para o desenvolvimento das nossas indústrias: O ensino técnico no contexto da lei orgânica do ensino industrial. História e educação, 41(17), 123-138. http://dx.doi.org/10.1590/S223634592013000300008. 
Bardin, L. (2009). Análise de Conteúdo. Edições 70: Lisboa, Portugal.

Bernardim, M. L. (2013). Juventude, escola e trabalho: Sentidos atribuídos ao ensino médio integrado por jovens da classe trabalhadora (Tese de Doutorado). Universidade Federal do Paraná, Curitiba.

Dalarosa, A. A., \& Souza, J. P. (2014). Orientações internacionais nas políticas de educação e trabalho para a juventude no contexto brasileiro. Conjectura: Filosofia e Educação, 19(2), 84-107. Recuperado em 29 de abril de 2019, de

http://www.ucs.br/etc/revistas/index.php/conjectura/article/view/2486/pdf 245.

Frigotto, G. (2013). Educação e qualificação de jovens e adultos pouco escolarizados: Promessa integradora num tempo histórico de produção destrutiva. Perspectiva, 31(2), 389-404. https://doi.org/10.5007/2175795X.2013v31n2p389.

Linhares, M. I. S. B. (2014). Aprendendo a ser trabalhador: Na cadência do primeiro passo. Revista Contraponto, 1(1), 7-22. Recuperado em 29 de abril de 2019, de https://seer.ufrgs.br/contraponto/article/view/46226/28809.

Nascimento, N. I. M. (2014). Exclusão social versus oportunidades: A estratégia discursiva das políticas públicas de juventude no Brasil. Revista Perspectivas Sociais, 3(1), 1-22. Recuperado em 29 de abril de 2019, de https://periodicos.ufpel.edu.br/ojs2/index.php/percsoc/article/view/2459/2 771.

Netto, J. P. (2011). Introdução ao estudo do método de Marx. São Paulo, SP: Expressão Popular.

Pelissari, L. B. (2012) O fetiche da tecnologia e o abandono escolar na visão de jovens que procuram a educação profissional técnica de nível médio. (Dissertação de Mestrado). Universidade Federal do Paraná, Curitiba. Recuperado em 29 de abril de 2019, de https://acervodigital.ufpr.br/bitstream/handle/1884/27670/R\%20$\% 20 D \% 20-$

\%20PELISSARI\%2c\%20LUCAS\%20BARBOSA.pdf?sequence=1\&isAllowed=y

Porchman, M. (2013). Juventudes na transição para a sociedade pós-industrial. In J. Macambira, \& F. R. B. Andrade (Eds.), Trabalho e formação profissional: Juventudes em transição. (pp. 37-56). Fortaleza: IDT, UECE.

Puerta, B. M. G., \& Aznarte, M. T. D. (2013). Reforma laboral en España: Precariedad, desigualdad social y funcionamiento del mercado de trabajo. Estudios Socio-juridicos, 15(2), 41-71. Recuperado em 29 de abril de 2019, de

https://revistas.urosario.edu.co/index.php/sociojuridicos/article/viewFile/25 $19 / 2320$. 
Sá-Silva, J. R, Almeida, C. D., \& Guindani, J. F. (2009). Pesquisa documental: Pistas teóricas e metodológicas. Revista Brasileira de História \& Ciências Sociais, 1(1), 1-15. Recuperado em 29 de abril de 2019, de https://www.rbhcs.com/rbhcs/article/view/6/pdf.

Silva, L. P. (2010). Formação profissional no Brasil: O papel do Serviço Nacional de Aprendizagem Industrial - SENAI. História (São Paulo), 29(1), 394-417. http://dx.doi.org/10.1590/S0101-90742010000100022

Souza, C., Paiva, I. L., \& Oliveira, I. F. (2014). Que política é essa? Um olhar sobre as políticas de juventude no Brasil. In I. L. Paiva, M. A. Bezerra, G. S. N. Silva, \& P. D. Nascimento (Eds.), Infância e Juventude em contextos de vulnerabilidades e resistências. São Paulo: Zagodoni.

Sposati, A. (2010) Topografia social da cidade de João Pessoa. Cedest/IEE/PUCSP.

Tommasi, L. (2014). Juventude, projetos sociais, empreendedorismo e criatividade: Dispositivos, artefatos e agentes para o governo da população jovem. Passagens. Revista Internacional de História Política e Cultura Jurídica, 6(2), 287-311. Recuperado em 29 de abril de 2019, de https://www.redalyc.org/articulo.oa?id=337330681005.

Vygotski, L. S. (2006). Obras escogidas. Madrid: Visor.

\section{Sobre os autores}

Manuella Castelo Branco Pessoa, é psicóloga, mestre em psicologia e doutora em psicologia social pela Universidade Federal da paraíba (UFPB), com pós-doutoro em Psicologia da saúde na linha Trabalho, saúde e subjetividade pela Universidade Estadual da Paraíba (UEPB). Atualmente é professora adjunta no departamento de psicologia da UFPB, professora colaboradora no Programa de Pós-graduação em Psicologia da Saúde da UEPB e vice-líder do Núcleo de Pesquisas e Estudos sobre o Desenvolvimento da Infância e Adolescência (Nupedia-UFPB). Email: manucastelobranco2@gmail.com

Maria de Fatima Pereira Alberto, é psicóloga pela UFPB, mestre em Serviço Social pela UFPB e doutora em Sociologia pela Universidade Federal de Pernambuco (UFPE). Atualmente é professora associada da UFPB, do Programa de PósGraduação em Psicologia Social (mestrado e doutorado) e líder do Núcleo de Pesquisas e Estudos sobre o Desenvolvimento da Infância e Adolescência (Nupedia-UFPB). Email: jfalberto@uol.com.br Orlando Junior Viana Macêdo, é psicólogo, mestre e doutor em psicologia pela Universidade Federal da Paraíba. É professor no curso de psicologia Faculdade Paraíso (FAP) e Faculdade Juazeiro do Norte (FJN), e membro do Núcleo de Pesquisas e Estudos sobre o Desenvolvimento da Infância e Adolescência (Nupedia-UFPB). Email: orlandojrvm@yahoo.com.br Antonia Picornell Lucas, possui graduação em Filosofia e Ciências da Educação Universidad de Salamanca (USAL-Espanha) e doutorado em Historia de la 
Educación (USAL). É professora em serviço social na USAL e Presidente da Red Iberoamericana para la Docencia e Investigación en Derechos de la Infancia (REDidi). Email: toi@usal.es

Manuella e Fatima contribuíram para a conceitualização, investigação e visualização do artigo; Orlando e Antonia fizeram parte da redação inicial e redação final (revisão e edição), juntamente com Manuella e Fatima.

Os autores agradecem a CAPES pelo financiamento da pesquisa através de uma bolsa de doutorado da autora principal.

Recebido em: 04/04/2017

Revisado em: 30/09/2017

Aceito em: 12/01/2018 